\title{
Increase of anaerobic polymer materials resistance to vibration loads and working fluids using nanofillers
}

\author{
Alexandr Kononenko ${ }^{1}$, Alexander Mikhalchenkov ${ }^{2}$ and Anastasiya Zabavina ${ }^{1,}{ }^{*}$ \\ ${ }^{1}$ Bauman Moscow State Technical University, 5-1, 2-ya Baumanskaya Str., Moscow, 105005, \\ Russian Federation \\ ${ }^{2}$ Bryansk state agrarian University, 2A, Soviet Str., the village of Kokino, Vygonichskogo district, \\ Bryansk region, 243365, Russian Federation
}

\begin{abstract}
The operation of modern machines and equipment is impossible without technical service, which accounts for up to $35 \%$ of the total structure of operating costs. Therefore, ensuring timely maintenance with minimal downtime at the lowest cost is a vital task. One of the resource-defining elements of machines is bearing units, and increasing their durability is a promising direction. The analysis of defects occurring in bearing units showed that the main cause of surfaces wear under rolling bearings is fretting corrosion which occurs due to the impossibility to have an effective contact spot with an area of more than $35 . . .40 \%$ in cylindrical joints. There are many ways to restore parts, but due to the high competitive capabilities polymeric compounds methods are widely used. Such materials allow quick repair, they also increase the resource of individual nodes and, as a consequence, the entire renovation object as a whole. Due to their performance characteristics, polymers have been widely used both in manufacturing and in renovation of parts and units operating under severe dynamic loads and aggressive environments. However, they have insufficient resistance to vibration loads and aggressive working fluids. The solution to this problem is the development of new polymer nanocompositions based on anaerobic compositions using dispersed nanofillers. Due to the high surface energy of nanoparticles their introduction into the polymer matrix will increase adhesion strength, resistance to vibration and impact of working fluids.
\end{abstract}

\section{Introduction}

Bearing units are widely used in the design of modern equipment. Damage to bearing seats is inevitable in conditions of heavy loads, and operation of shafts in most cases is not allowed if the surfaces wear is more than $0.02 \mathrm{~mm}$. During machine operation, all parts and connections are exposed to vibration loads which reduces their durability. Rolling bearings, in turn, are additional sources of vibration over a wide range of frequencies. The level of disturbances generated by bearings depends on their size, accuracy class and load. The

\footnotetext{
* Corresponding author: anastasia.andreevna@bmstu.ru
} 
nature of vibrations in rolling bearings is very complex and diverse [1]. The deformation of bearing seats areas happens as a result of many complex processes that occur at the contact point of shafts and inner rings of bearings. Due to intense loads and vibrations, the main cause of wear of bearing seats areas and, consequently, reduction of the durability of the unit as a whole is the fretting corrosion which results in cranking of the inner rings of bearings during operation [2].

Fretting corrosion occurs on contacting surfaces at their mutual micromovements under the influence of vibrations. The intensity of wear is associated with the abrasive action of fracture products formed during friction which have a high abrasion ability because they are more firm than the base metal. Since the release of fretting particles from the contact zone is difficult, they gradually accumulate and lead to an increase in pressure and in the area of damage of the base metal. Therefore, the issue of eliminating this defect is quite acute [3].

Restoration of the shaft-bearing connection with polymer materials is a technologically justified and effective replacement of known traditional methods, such as surfacing, spattering, electrolytic build-up requiring the use of expensive equipment and highly qualified specialists. When using polymers, there is no thermal impact on the part, there is no need for additional machining after recovery, the problem of direct contact of metal surfaces is solved thus eliminating the possibility of fretting corrosion. These methods are the most economical, they are characterized by low labor intensity, do not require special equipment or high qualification of personnel, and also provide high durability in restored nodes. The use of polymer materials in the repair of equipment allows to reduce: labor intensity by $20 . . .30 \%$, cost of repair by $15 \ldots 20 \%$, material consumption by $40 . .50 \%$. One of the main advantages of using polymeric compositions in restoration works is the possibility of increasing the contact area of the contacting surfaces in a fixed connection practically up to $100 \%$, which reduces the coefficient of uneven load distribution between rolling bodies in the bearing and, consequently, increases the durability of the entire unit. In addition, polymers can be applied on the surfaces of various sizes and configurations providing the required coating thickness. [4].

Different types of polymer materials are used to restore the connecting surfaces of parts. Thus, epoxy compositions are widely used, the advantage of which is the fact that the pressing-out force of the restored fixed compound is 2 ... 3 times higher compared to the press fitting without polymer coating, and the resistance of shafts and axles to variable loads increases to $40 . . .75 \%$. However, this application has a number of limitations: lack of durability, strict adherence to component proportions, mechanization or automation of the process, the use of special devices. The minimum thickness of the applied layer of epoxy composition is more than $0.5 \mathrm{~mm}$, which practically excludes its use for fitting restoration in bearing units [5].

In recent years the practice of world mechanical engineering and repair production have been using anaerobic sealants which are multicomponent liquid compositions that can be stored for a long time without changing properties and can be quickly polymerized in narrow gaps between metal surfaces in case of violation of contact with air oxygen [6]. The setting time of anaerobic sealants, the curing rate, the time of reaching the maximum strength of the adhesive compound and the time of the working strength set depend on the temperature, the activity of the metal and the size of the gap. The disadvantages of anaerobic polymer compositions are their low elastic properties, as well as their level of resistance to working fluids and vibration loads. However, modification of polymer material allows to improve these properties [7].

A promising direction in obtaining completely new materials used for restoration of fixed joints of rolling bearings is the creation of polymer nanocompositions based on anaerobic sealants. The effect of the filler on the property of the composition depends on the size of its grains, the concentration in the system and the chemical nature of the polymer 
matrix. Due to the high surface energy of fillers, their introduction into the polymer matrix improves adhesion properties and resistance to operational loads [8-13]. In the paper $[14,15]$ it is noted that the peculiarity of modification of polymer materials by nanoparticles is the increase polymer matrix adhesion to the surface of nanoparticles, uniform distribution of nanoparticles along the matrix volume and ultra small concentrations of modifiers. The introduction of nanoparticles reduces the diffusion coefficient several times, as well as increases the ultimate strength of the polymer material. All these factors will contribute to increasing the technical resource of nanocomposite materials by more than 1.5 times compared to that for traditional composites.

\section{Materials and Research Methods}

Currently, the polymers market is very diverse and Loctite brand is widely used in repair production. To study the resistance of polymeric anaerobic compositions and nanocompositions based on them to vibration loads and working fluids, we used the polymeric anaerobic composition Loctite-638 and its Russian analogue Anakrol-101 together with nanomodifications of these materials. DEALTOM carbon nanotubes (hereinafter referred to as CNT) and nanosized alumina $\alpha$-type oxide produced by Center of Nanotechnologies RPE (hereinafter referred to as " $\mathrm{Al}_{2} \mathrm{O}_{3}$ ") with concentration of 0.5 and 1.0 per cent by mass respectively. Nanocompositions were obtained by means of mechanical mixing of polymer material with $\mathrm{Al}_{2} \mathrm{O}_{3}$ and $\mathrm{CNT}$ for $60 \mathrm{~s}$ and subsequent ultrasound treatment for $30 \mathrm{~s}$ for better distribution of nanoparticles in the volume of the composition.

The durability tests of bearing units in production conditions require a long time, have high labor intensity and are associated with the difficulties of taking into account various factors arising during the operation of machines. Bench tests with vibration loading simulating the real conditions of operation of the equipment, allow with minimal cost of money and time to obtain the basic dependencies to be kept in mind during operation. Therefore, to carry out research of resistance of sealants and nanocompositions on their basis to vibration loads, a unit based on electromechanical vibrator IV-107, which is an asynchronous squirrel-cage induction motor with a rated power of $800 \mathrm{~W}$, a speed of $46.6 \mathrm{~s}^{-}$ , exciting force of $10 \mathrm{kN}$, static torque of $1.15 \mathrm{Nm}$ and mass of $51 \mathrm{~kg}$ (fig. 1). The motor was mounted on a metal platform weighing $130 \mathrm{~kg}$, which, in turn, was installed on four cylindrical screw springs. These springs were selected so that the frequency of the own oscillations of the plate and the motor fixed on it, was $20 \%$ of the frequency of forced oscillations. The amplitude of the plate oscillations measured by the VR-1 vibrograph was $2.5 \mathrm{~mm}$. Experimental samples glued by polymeric compositions and nanocompositions based on them were rigidly fixed on the plate. 


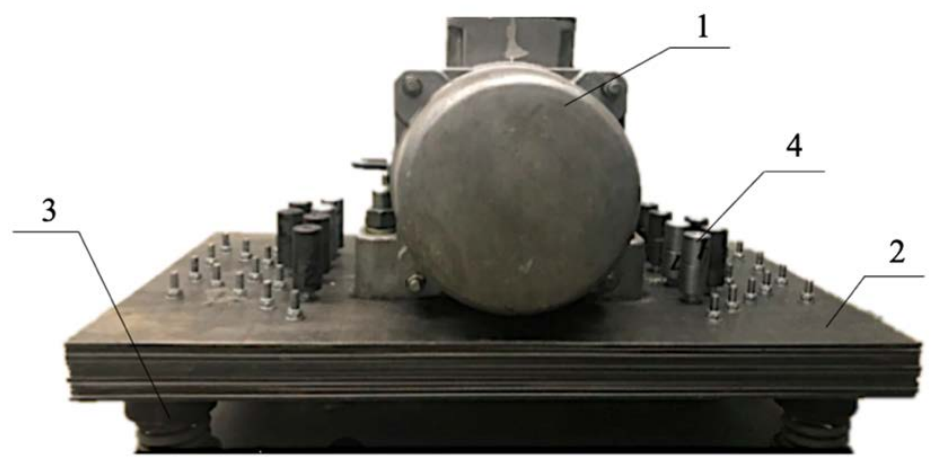

Fig. 1. General view of the stand to test vibration resistance of polymeric compositions: 1electromechanical vibrator IV-107, 2-metal platform, 3-cylindrical screw springs, 4-experimental samples.

After exposure to vibration loads on the samples for 5, 10, 15, 20, 25 and 30 hours, the adhesion peel strength tests were carried out at normal breaking stresses at SATEC Instron pull test machine.

In the study of sorption-diffusion interaction with polymers, motor, transmission and industrial oil were used as working fluids. Films of the studied compounds with thickness of $0.2 \mathrm{~mm}$ after polymerization were cleaned in detergent, dried and kept in desiccator, then weighed on Sartorius electronic scales with accuracy $10^{-4} \mathrm{~g}$. After keeping samples in working fluids for $1-1176$ hours at room temperature they were also cleaned, dried and weighed.

The change in the mass of the sample before and after exposure to the working fluid $\left(m_{0}\right.$ and $m$, g respectively) was determined by formula 1 :

$$
q=\frac{m-m_{0}}{m_{0}} \times 100 \% \text {. }
$$

To study the influence of nanoscale fillers on anaerobic polymer nanocompositions resistance to working fluids, Loctite-638 and Anakrol-101 materials were mechanically mixed with nanostructured aluminum oxide $\left(\mathrm{Al}_{2} \mathrm{O}_{3}\right)$ and carbon nanotubes $(\mathrm{CNT})$, then ultrasonic treatment was performed for better distribution of nanoparticles in the composition volume.

The analysis of nanostructure samples was carried out in semi-contact mode (AC Air Topography) on scanning probe microscope MFP-3D (Asylum Research, USA) with the use of NSG01 cantilver (Tipsnano) with hardness of $4 \mathrm{~N} / \mathrm{m}$ and a resonant free oscillation frequency of $120 \mathrm{kHz}$. Processing of the received images was carried out in IgorPro software.

\section{Results and Discussion}

The results of experimental studies of Loctite-638 and Anakrol-101 compositions and nanocompositions based on them resistance to vibration loads are presented in fig. 2 . The analysis showed that with the increase in the number of test cycles, the adhesion strength of the compositions decreased. Thus, after 30 hours of testing, the overall reduction in adhesion strength was $47.2 \%$ for Loctite composition, $46.3 \%$ for CNT nanocomposition, and $35.6 \%$ for $\mathrm{Al} 2 \mathrm{O} 3$. 
Anakrol composition and nanocomposition thereof had higher indicators. Thus, in unfilled composition the strength characteristics under similar conditions decreased by $61.3 \%$, and in nanocompositions with $\mathrm{CNT}$ and $\mathrm{Al}_{2} \mathrm{O}_{3}$ - respectively by 59.1 and $47.7 \%$. Thus, the analysis of the research results showed that the intensity of reduction of strength characteristics in nanocompositions with CNT under the influence of vibration loads practically does not differ from unfilled compositions. Unlike $\mathrm{CNT}, \mathrm{Al}_{2} \mathrm{O}_{3}$ led to an increase in the durability of the initial compositions by 11.6...13.8\%.

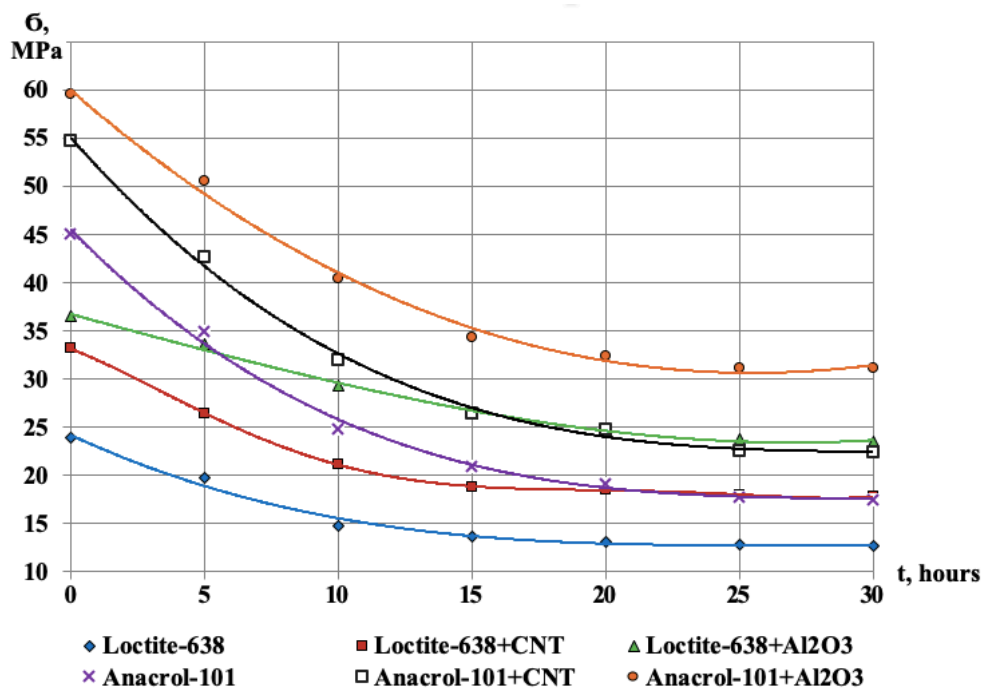

Fig. 2. Influence of nano-fillers on the change of polymeric compositions of adhesive strength under the influence of vibration loads

Thus, the modification of sealants by nano-fillers increases their resistance to vibration up to $13.8 \%$. Nanoscale aluminum oxide has the greatest impact on increasing the resistance of nanocompositions to vibration loads.

Studies of anaerobic polymer compositions and nanocompositions based on them resistance to working fluids showed that as a result of contact of polymer material surface with the technological medium, its physical and mechanical properties change and, as a result, its operational parameters deteriorate. Under the influence of working fluids processes of swelling and dissolution of components of polymer compositions occur simultaneously which affects their durability. When the studied Loctite-638 and Anakrol101 compositions contacted motor, industrial and transmission oil, there was an increase in the weight of the samples, that is, the swelling process prevailed.

Interaction of Loctite-638 samples with working fluids begins with a rapid increase in sample mass as a result of swelling (fig. 3). 


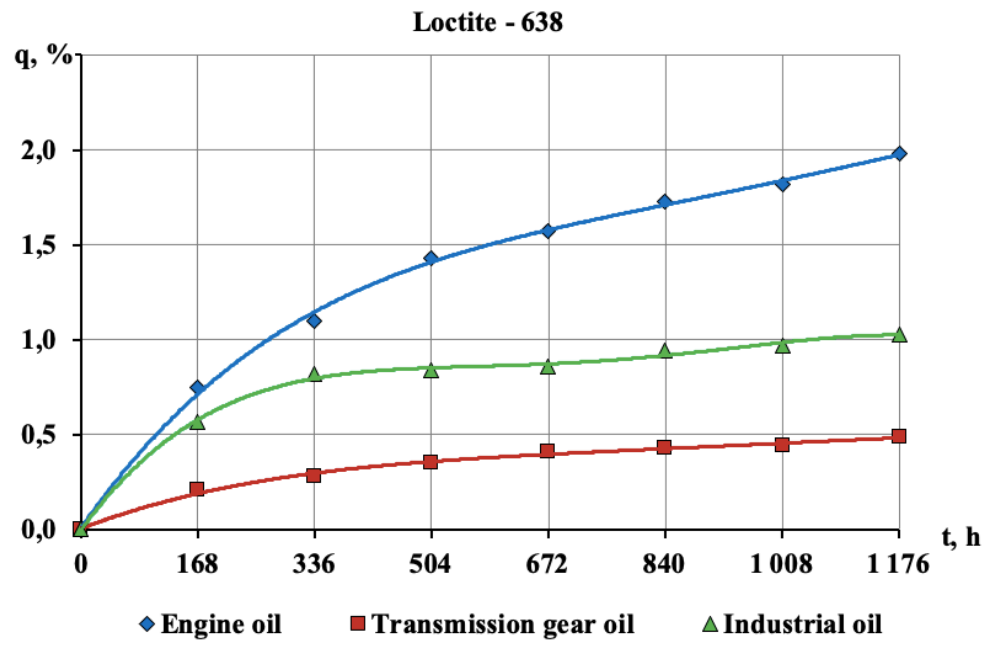

Fig. 3. Sorption and diffusion interaction of Loctite-638 composition with working fluids

The greatest increase in the mass of Loctite-638 polymer composition (up to 2.0\%) occurred in contact with motor oil for $1176 \mathrm{~h}$, after which this process stabilized. In industrial and transmission oil, intensive swelling of samples stopped after $504 \mathrm{~h}$. As a result, the increase in their mass compared to the initial values was $0.49 \%$ and $0.98 \%$ respectively.

Anakrol-101 composition has better resistance compared to Loctite-638 (fig. 4). The swelling process of Anakrol-101 samples in industrial and transmission oil is more intensive than in motor oil and is respectively $0.87 \%, 0.61 \%$ and $0.28 \%$. The stabilization of the process in these working fluids occurs only after $1008 \mathrm{~h}$, while in motor oil the swelling slows down already after $504 \mathrm{~h}$.

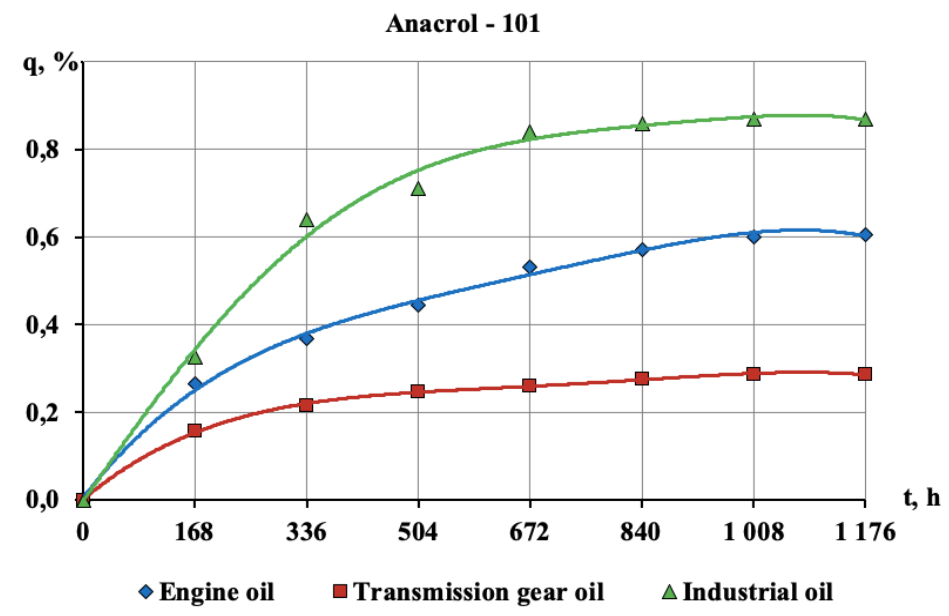

Fig. 4. Sorption and diffusion interaction of Anakrol-101 composition with working fluids

The results of studies of nanoscale fillers influence on the resistance of anaerobic polymer nanocompositions to the influence of motor, transmission and industrial oil showed that depending on the of the liquid type, the resistance of the Loctite-638 composition filled with $\mathrm{Al}_{2} \mathrm{O}_{3}$ nanoparticles is $2-2.5$ times higher than the resistance of the initial composition, and for the modified CNT $-1.7-2.2$ times. The best performance is achieved in nanocomposition based on Loctite-638 with the addition of $\mathrm{Al}_{2} \mathrm{O}_{3}$. The 
resistance to the investigated liquids of Anakrol-101 composition modified by $\mathrm{Al}_{2} \mathrm{O}_{3}$ is higher than that of the initial composition by 2.1-3.0 times, and for the filled CNT — by 1.7-2.5 times, depending on the type of working fluid. The best indicators were observed in nanocomposition based on Anakrol-101 with $\mathrm{Al}_{2} \mathrm{O}_{3}$.

It is important to note that due to prolonged contact of experimental samples with transmission and industrial oil, changes in their color occurred. Thus, Loctite-638 samples have only slightly lost color saturation and became more transparent. And Anakrol-101 samples got the color of working fluids. At the same time, the color change in nanomodified compositions was less intense than in unfilled polymers.

The analysis of nanostructure samples allowed to assess in detail the reasons for changing the resistance of nanocompositions to vibration loads and working fluids. The studied nanoparticles have different sizes and structure. The $\mathrm{Al}_{2} \mathrm{O}_{3}$ nanoparticles have a diameter of about $50 \mathrm{~nm}$, and CNT - from 10 to $30 \mathrm{~nm}$. Studies have shown that nanoparticles contribute to the increase in the size of the fibers of the polymer matrix sealants. The size of polymeric fibers of the unfilled Loctite-638 sealant after mixing it with CNT and $\mathrm{Al}_{2} \mathrm{O}_{3}$, processing in ultrasonic field and full polymerization increased respectively by 130 and $75 \%$ (fig. 5). When structuring Anakrol-101 composition with CNT and $\mathrm{Al}_{2} \mathrm{O}_{3}$, nanoparticles were also evenly distributed around polymer fibers, with their size increasing by 175 and 125\% respectively (fig. 6). The distance between the fibers in all the studied compositions has also increased. Nanocompositions with $\mathrm{Al}_{2} \mathrm{O}_{3}$ have the most uniform structure

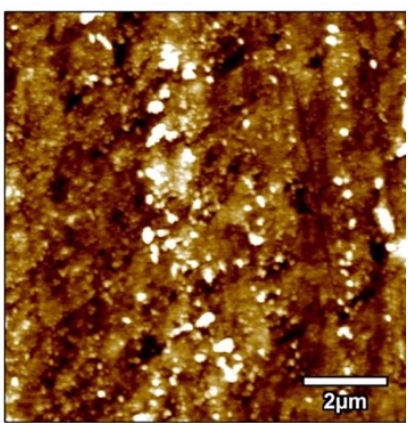

a

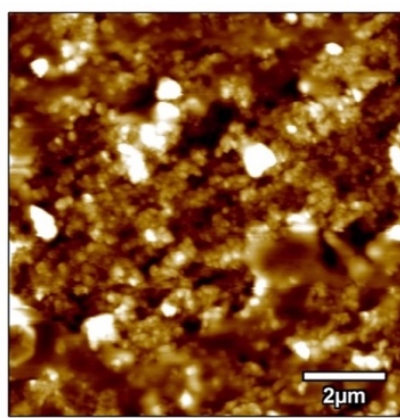

b

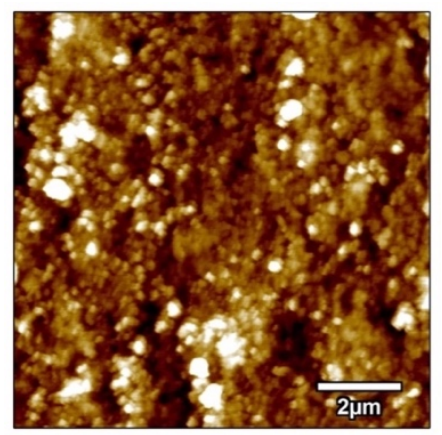

C

Fig. 5. Scans of Loctite-638 surfaces and nanocompositions thereof: a - unfilled polymer; b polymer $+\mathrm{CNT}$; c - polymer $+\mathrm{Al}_{2} \mathrm{O}_{3}$

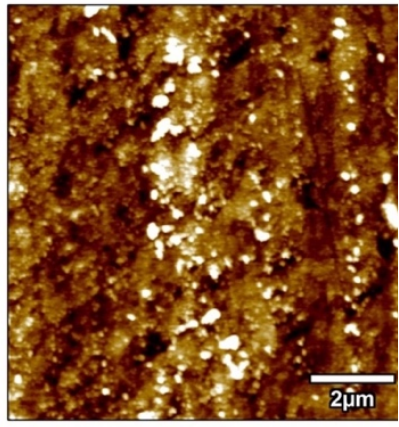

a

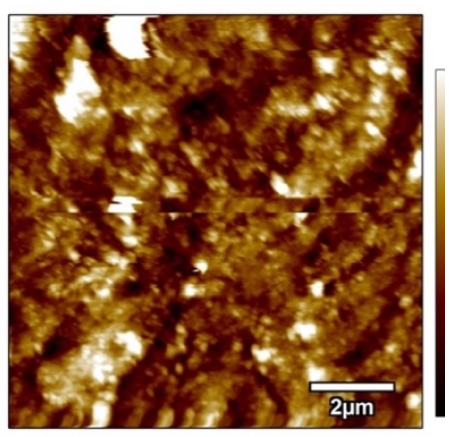

b

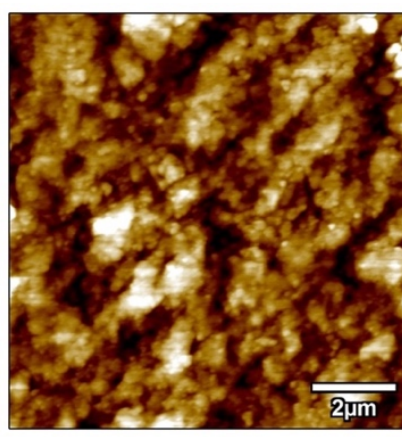

C

Fig. 6. Scans of Anakrol-101 surfaces and nanocompositions thereof: a — unfilled polymer; b polymer $+\mathrm{CNT} ; \mathrm{c}-$ polymer $+\mathrm{Al}_{2} \mathrm{O}_{3}$ 
Thus, the analysis of polymer compositions nanostructure showed that when mixing them with nanoparticles, the size of polymer fibers, the distance between them, and therefore the properties of the obtained compositions change. This is due to the high surface energy of nanoparticles, thanks to which they interact intermolecularly with polymer fibers and are distributed around them by means of weak Van der Waals forces. The developed surface of the filler and the ordered arrangement of polymeric chains increases the resistance of nanocompositions to vibration loads due to their more uniform distribution throughout the whole volume of compositions. With increasing the thickness of the fibers, elastic properties of polymers increase, and due to decrease in the mobility of polymeric chains, the possibility of sorption-diffusion interaction with external media, which leads to an increase in the resistance of nanocompositions to the effects of working fluids, decreases. Analyzing the above, we can conclude that the use of nanofillers contributes to increasing the durability of sealants.

\section{Outcomes}

1. To restore bearing units it is advisable to use polymeric anaerobic nanocompositions, the durability of which depends on many factors, including resistance to vibration loads and to the effects of working fluids.

2. Modification of anaerobic polymer materials by nanofillers significantly (up to 3.0 times) increases their resistance to the effects of working fluids, increases their resistance to vibration loads up to $13.6 \%$.

3. The greatest effect is achieved by modifying the Russian polymer composition Anakrol101 with nanoscale aluminum oxide.

4. When mixing anaerobic compositions with nanoparticles, the size of polymeric fibers increases, which leads to a decrease in their mobility, which explains the increase in resistance to vibration loads and working liquids, positively affecting the durability of the resulting compositions.

\section{References}

1. Li R.I. A promising polymer composite material for increasing the efficiency of recovery of basic parts of automotive engineering / Li R.I., Butin A.V., Ivanov S.P., Mashin D.V. // Polymer Science. Series D. 2014. T. 7. № 3. Pp. 233-237.

2. Alekseeva L.B. Sources of vibrations in metal-cutting machines and in electric machines // Modern problems of the theory of machines. - 2015. - № 3. - Pp. 79-81.

3. Petukhov A.N. Fretting and fretting fatigue in non-mobile joints // Friction and lubrication in machines and mechanisms. 2013. № 2. Pp. 17-19.

4. Aronovich D.A., Hamidulova Z.S., Murokh A.F. Modern developments of the Research Institute of Polymers in the field of acrylic adhesive materials // News of Materials Science. Science and Technology. 2016. № 2 (20). P. 8.

5. Mikhal'chenkov A.M., Torikov V.E., Filin Y.I. The influence of the concentration of components of an epoxy-sandy composite on its abrasive-wear resistance // Polymer Science. Series D. - 2018. - T. 11. - № 1. P. 47-49.

6. Ustyuzhantseva N.A., Aronovich D.A., Balashov S.V., Zhukova G.A. Influence of structural acrylic adhesive components on adhesive properties when glueing different materials // Adhesives. Sealants, Technologies. 2016. № 6. Pp. 7-12. 
7. Kononenko A.S., Kildeev T.A., Solovyova A.A. Features of restoration of spindle shafts of metal-cutting machines using polymeric materials and nanocomposites thereof// Repairs, Restoration, Modernization. 2018. № 10. Pp. 3-8.

8. V.A. Nelyub, A.S. Borodulin, L.P. Kobets, G.V. Malysheva. Thixotropy hysteresis and structure formation in elastomeric suspensions. Inorganic Materials: Applied Research. 2018. Vol. 9. № 4. pp. 603-608.

9. P.A. Belov, A.S. Borodulin, L.P. Kobets, G.V. Malysheva. Kinetics of fiber impregnation by a binder, radient generalization of navier-stokes-darcy equations. Polymer Science. Series D. 2016. Vol. 9. № 2. pp. 205-208.

10. V.A. Nelyub, A.S. Borodulin, L.P. Kobets, G.V. Malysheva. Viscous hysteresis in filled siloxane binders. Polymer Science. Series D. 2017. Vol. 10. № 1. pp. 19-22.

11. P.P. Maung, G.V. Malysheva, S.A Gusev. A study of the effect of network angle of fabrics on kinetics of impregnation upon molding of articles made from carbon plastics. Polymer Science. Series D. 2016. Vol. 9. № 4. pp. 407-410.

12. V.A. Nelyub, A.S. Borodulin, L.P. Kobets, G.V. Malysheva. A study of structure formation in a binder depending on the surface microrelief of carbon fiber. Polymer Science. Series D. 2016. Vol. 9. № 3. pp. 286-289.

13. Mikhal'chenkov A.M., Kozarez I.V., Tyureva A.A., Kuz'min V.N. Procedure for comparative accelerated testing of materials for resistance to abrasive wear as they move in a loose abrasive environment // Polymer Science. Series D. 2018. T. 11. № 1. P. 110-112.

14. Kononenko, A.S. Restoration of bearing seats areas under rolling bearings in the body parts of machines using polymeric nanocomposites [Text] / A.S. Kononenko, I.A. Kuznetsov // Works of GOSNITI. 2016. Vol. 124 (2). Pp. 81-85.

15. A.S. Kononenko, A.A. Solovyeva Performance characteristics of new polymer anaerobic nanocompounds for the bearing units repairing. Materials Today: Proceedings. 2019. doi:10.1016/j.matpr.2019.07.040 